\title{
Comment: Knowledge Transfer - Risks and Possibilities
}

\author{
By Penny Harvey (University of Manchester)
}

The papers by Allen, Shapiro and Downing and are all concerned in different ways with questions of 'knowledge transfer' in cases where knowledge is openly contested, where it disappoints, or fails to deliver the enhanced understandings or capacities that it seemed to promise. The generation and communication of anthropological knowledge is folded into these discussions. What is going on when knowledge fails to travel well? What expectations of knowledge, of travel and of transformation are in play?

Allen's account of a technology transfer project that involved women from Ethiopia travelling to India to learn how to assemble and maintain solar photovoltaic energy circuits offers a detailed account of the difficulties encountered by people who learn how to do things in one context (or set of relations) and attempt to activate that knowledge in another. In this case the women appeared to have learnt what they needed to know in order to be able to install and maintain these systems in their own communities. But it turned out that a specific technical proficiency achieved in the training environment in India (achieved despite the difficulties produced by a lack of English) was not sufficient for them to install and maintain these systems at home.

As I read Allen's account I began to think about the instructions that IKEA provide with their flat-pack, self-build furniture. The company assumes no common language and the instructions for assemblage are entirely non-verbal. Such instructions would, in Allen's terms, comprise explicit knowledge. I use the example because in the end, despite the struggle, most people do manage to build the furniture, more or less as intended. My point is that manuals, and explicit instructions, can and often do effectively communicate how to go about building the item in question, and I for one, find it easier to assemble a flat-pack with the instructions than without them. However, the difficulties that I invariably experience along the way also indicate that the instructions in and of themselves are not quite enough. Other things (materials, skills, bodily capacities, relations) are required. Allen is interested in what it is that explicit knowledges conceal, the tacit knowledges required to make them work.

The IKEA customer needs bodily capacities and skills, some basic tools and some prior knowledge of how to use them, a notion of what is being built and the ability to evaluate whether what emerges is adequate. And while wood-working or craft skills would certainly help in this process, they are not necessary. You don't have to have more than minimal craft skills to assemble your flat-pack, that is the point. The manufacturers know how the thing should fit together, and they seek to pass that knowledge on to the purchaser using the combination of pre-prepared parts and visual images to direct their assemblage. 
So: what happened that resulted in the women being unable perform the basic work necessary to install and maintain the solar powered circuits in their home communities? What exactly was missing that prevented them from finding their own ways around the problems that arose. The technologies were simple, and the women had learned to do the things they needed to do to keep them going. The success of the IKEA flatpack suggests that people routinely produce their own tacit knowledge to get things working. A more apposite parallel can be found in de Laet \& Mol's (2000) discussion of a 'bush-pump' introduced to Zimbabwe with outstanding success. This simple technology worked because the pumps caught people's interest, people loved them and cared for them, and found ways to keep them going. Thinking of the bushpump I wondered whether, in the end, there were other impediments to the adoption of the solar circuits beyond issues of explicit and tacit knowledge. Did people in the end perhaps not prioritise the need for solar power over and above the other things that occupied them day in and day out; when people 'forget' how to do something there is an implication of distraction, of competing demands, of other interests; it might even be that during their time in India the women learned other things, about themselves, about the world, that mattered more to them than an attempt to become 'solar engineers' in their home communities. While agreeing with Allen's general ANT line that knowledge is an emergent phenomenon performed between a range of heterogeneous actors (human and non-human) we really need to know more about who or what these actors were in the African context. Rather than a tale of lost knowledge, it might (also) be a tale of new additions and distractions that upset the focused simplicity of the Indian training sessions.

Matan Shapiro's paper addresses what he terms 'affective knowledge' and focuses primarily on the importance of omissions and half-truths in the dynamic circulation of stories and rumors associated with sexual activity, emotional relations and moral values more generally among people in NE Brazil. Shapiro points out that effective communication does not rest with the establishment of a singular authoritative 'truth'. More important are the ways in which people set out to persuade, or seduce others into recognising or adopting their point of view. Shapiro is interested in the overlaps between the half-truths and the omissions that sustain Maranhão sociality, and the half-truths and omissions that he detects in much anthropological writing. But there are asymmetries here. By contrast to the productively wily effects of the Maranhão omissions, the half-truths of the anthropological analysts are presented as a barrier to understanding, and a refusal to engage those issues which most fascinate Shapiro, the ethnographer. But if the omissions and half-truths of the people of Maranhão are important for the ways in which they 'keep things going' - might this not also be worth consideration in relation to the world of the anthropologist who sets out to provide an analytical account of their fieldwork findings?

I am reminded of Taussig's (1987) wonderful rendition of Evans-Pritchard's sorcery, the 'duplicitous lucidity' of the master ethnographer who holds back to better enchant and in the process to enact a knowledge practice that echoes the masterful moves of the Azande sorcerers he was seeking to describe (Taussig 1987). Taussig's appreciation of Evans-Pritchard's rhetorical skills do not address the omissions and half-truths that have occupied critics writing from different perspectives and in different genres, particularly Evans-Pritchard's failure to challenge an image of the Azande that concealed their participation in a world of political conflict and religious diversity. Evans-Pritchard may have disappointed readers who wanted to know about 
wider questions of political economy and social inequality, but he had much to teach those who wanted to know about sorcery.

Shapiro's work invites us to reflect on the relationship between anthropological knowledges and the knowledges of those we study. As ethnographers we learn in many ways: some of us set out to learn how to live appropriately and successfully in specific environments, some of us settle for learning as much as we can about how other people live appropriately and successfully without ever becoming skilled practitioners ourselves; some of us set out to try and understand how specific ways of acting (discursive and non-discursive) make sense, how they work as meaningful (cultural) activities; others are more drawn to asking how the particular phenomena that present themselves in the field come about, how specific relational dynamics are sustained or reproduced. These interests are certainly not mutually exclusive, but they don't necessarily intersect. Any one of them could feasibly sustain a credible performance of anthropological knowledge. Scheper-Hughes is chastised by Shapiro for her failure to take seriously the local assertion that babies who die of starvation were actually angels who thus did not require food; and Hautzinger is also criticized for her insistence that marital infidelity is adulterous rather than an expression of love as the people of Salvador insisted. I have sympathy with the critique and would perhaps have been more inclined than these authors to follow the leads that were offered in the field. However, in terms of the performance of anthropological knowing, these authors are highly successful, they persuade and convince, they engage others. Perhaps this is the dilemma - not the 'gaps' and 'omissions' per se, but the fear that the seductive power of these writers works through an appeal to common, but unexamined assumptions which are reinforced, rather than challenged by their accounts.

Shapiro listened to other things, and had other stories to tell. His interpretations, and his interest in showing how people can 'bend and shape everyday inequalities' have to compete in a complex field of anthropological knowledge making. But the terms of the disagreement may need spelling out with a bit more clarity. Are all gaps and omissions equally problematic? Is the choice between the heroic discovery of prior realities and the collaborative negotiation of relational and contingent 'truths' quite as stark as presented here? I would suggest, that even in Shapiro's ethnographic writing, we can find a bit of both.

David Downing's contribution runs with similar issues. He is directly concerned with what makes knowledge credible and argues, following Haraway, that credibility is always local in character. This presents an interesting question, that links us back to Allen's paper. It is not unreasonable to assume that abstract knowledge travels well. The effort invested in producing modern scientific knowledge is precisely linked to the understanding that in order to travel, knowledge must be wrested away from the relations that bind it to specific contexts. The role of instruments, or protocols and standard practices are devices to effect this virtuous detachment in science. And diagrams and manuals play a similar role in technology transfer. So what should we make of the injunction that such knowledge has to be (made) local in order to become credible.

Downing is interested in the reductions and erasures that make stories travel well and easily draws from his analysis of the political controversies surrounding the 
introduction of genetically modified seeds in agricultural practice. He shows how the rhetoric of anti-GM campaigners produces a simplified world of clear boundaries where the complexities and diversity of GM practices and interventions are played down. The under-specification of what GM involves, is what allows the story to takeoff, and for a fertile and promiscuous analogizing to take place, gathering anxieties and building a pervasive aura of public concern. Scientific studies are also used to counter claims made by the GM promotors and their expert supporters. But the detail of scientific analysis is too local to science to be truly effective when it comes to galvanizing one of the few spaces that might effectively overturn established legal precedent - the space of public opinion and the credible expression of public interest. The challenge is to rouse public interest, and rhetoric is more effective than science in this space - or rather science needs rhetoric to launch and maintain its relevance in public debate.

Downing asks us to consider what ethnographers should do when confronted by what appear to them as exaggerated claims or blatant misinformation? How should we deal with the strategic transfer of ignorance such as he witnessed in the flow of stories that fuelled the GM controversies? The issue is particularly problematic when such tactics are skillfully deployed by those with whom one has sympathy. His work provides us with an answer: we should make such knowledge claims commensurate with others that might seem more true, by thinking about all knowledge making as local, as narrated, as rhetorical - and we should consider how stories get purchase, what other stories they have to compete with, what their presence places under threat, or allows to blossom.

I was left wondering about the knowledge transfer story in the Monsanto case. Proprietary knowledge travels in the modified seed. It is transferred without narrative and in a way that upsets common-sense notions of 'theft' as it carries 'property' unwanted into spaces for which others are responsible and liable in law. The paradox of the passive, unwilling and unmotivated appropriation produces a powerful sense of injustice, which gathering force via other analogous stories can effectively seep back into the GM debates by non-scientific routes - magnifying uncertainties and configuring 'official justice' as itself opaque and deceitful.

Ethnographic fieldwork requires anthropologists to immerse themselves in worlds of contradiction, ambiguity and uncertainty - lived experience, as yet untidied. The idea of following story-making, and lines of credibility is a very interesting research strategy that allows the researcher to follow misunderstandings, and even to watch the setting of false trails. But the GM seed also reminds us of the power of things - the entities that neither speak, nor are spoken of, but which nevertheless have potency and transformative capacity. The knowledges of priests, shamans, and sorcerers is also worth keeping in view in discussions of knowledge transfer, for these are fields of expertise that draw on a capacity to move between the tacit and the explicit, the hidden and the visible, and to acknowledge the risks involved in that most open-ended of procedures we find referred to as 'knowledge transfer'. 


\section{About the Author}

Penny Harvey is a Professor of Social Anthropology at the University of Manchester. She is also a Director at the ESRC Centre for Research on Socio-Cultural Change (CRESC) and co-ordinates the research theme on 'Topologies of Social Change'. She has carried out research in the Andean Region and in the Peruvian Amazon, in Spain and in the U.K., and has published widely on engineering practice, state formation, information technologies and the politics of communication.

\section{Bibliography}

de Laet, Marianne and Annemarie Mol. (2000), 'The Zimbabwe Bush Pump: Mechanics of a Fluid Technology', Social Studies of Science, 30 (2): 225-263

Taussig, M. (1987), 'To Become a Healer', in Shamanism, Colonialism and the Wildman: A Study in Terror and Healing, Chicago: Chicago University Press. pp. 447-467. 